WORLD

RESOURCES

INSTITUTE

\title{
LOCALLY LED CLIMATE ADAPTATION: WHAT IS NEEDED TO ACCELERATE ACTION AND SUPPORT?
}

\section{EXECUTIVE SUMMARY}

\section{Highlights}

Locally led adaptation, in which local actors have decision-making power in planning, implementing, and monitoring and evaluation, can play an essential role in achieving successful and sustainable adaptation.

- A literature review of over 70 evaluation materials found that local actors are often involved in adaptation interventions but not in making decisions around the finance, design, and implementation of adaptation activities that will affect them. Only 22 projects of those reviewed included notably strong locally led characteristics, although 138 projects out of 374 had some elements of locally led adaptation.

- Characteristics from the review that enable locally led adaptation include flexibility, investments in community leadership and local institutional capacities, and the reinforcement of adaptation across scales and programs.

- Barriers to locally led adaptation financing include lack of investment in local capacities to manage funds and adaptation processes, low levels of accountability from funders and implementing entities to local actors, and insufficient funding.

- Efforts to increase locally led adaptation action can focus on the following: encouraging flexible and iterative approaches to program design and implementation; including local actors in decision-making from start to finish; increasing technical capacity building; working with existing governance and finance mechanisms and networks to achieve scale and reduce transaction costs; and building the evidence base on locally led adaptation.

\section{CONTENTS}

Executive Summary ...................................

1. Introduction ......................................... 3

2. Landscape of Existing Investments ................ 4

3. Scope and Methodology ......................... 6

4. Locally Led Adaptation and How It Differs from

Traditional Stakeholder Engagement Efforts ........... 6

5. Common Challenges and Barriers.................... 8

6. Types and Intervention Areas of Investments ...... 8

7. Investment Characteristics and Design Trends

That Enable Locally Led Adaptation ................... 11

8. Conclusion ....................................... 16

Appendix A: Additional Information .................. 18

Appendix B: Compilation of the Locally Led Projects and Programs Cited in This Paper ...................20

Glossary ....................................... 24

Endnotes............................................. 25

References ....................................... 25

Working Papers contain preliminary research, analysis, findings, and recommendations. They are circulated to stimulate timely discussion and critical feedback, and to influence ongoing debate on emerging issues. Working papers may eventually be published in another form and their content may be revised.

Suggested Citation: Tye, S., and I. Suarez. 2021. "Locally Led Climate Adaptation: What Is Needed to Accelerate Action and Support?” Working Paper. Washington, DC: World Resources Institute. Available online at https://doi.org/10.46830/

wriwp.20.00039. 
List of Abbreviations

BRACED Building Resilience and Adaptation to

Climate Extremes and Disasters

- CBA community-based adaptation

- CCCF County Climate Change Funds (initiative in Kenya)

- CDD community-driven development

- CSOs civil society organizations

- DCF Decentralising Climate Funds

- EbA Ecosystem-based Adaptation

- GCF Green Climate Fund

- GEF Global Environment Facility

- GIZ German Society for International Cooperation

- IIED International Institute for Environment and Development

- LDCs Least Developed Countries

- LoCAL Local Climate Adaptive Living Facility (a United Nations Capital Development Fund funding mechanism)

- NGO nongovernmental organization

\section{Context}

Despite the recognized need for climate adaptation efforts to be participatory, contextspecific, and fully transparent, finance for local adaptation is still severely lacking, and the voices and concerns of local actors who are at the forefront of climate impacts have generally not been meaningfully included in deciding how interventions are financed, designed, and implemented (Mfitumukiza et al. 2020; Dinshaw and McGuinn 2019). The majority of adaptation planning still occurs at the international and national levels, with local institutions and actors participating on the margins and as beneficiaries instead of as agents of change (IIED forthcoming). More must be done to enable locally led adaptation, increase local efforts and capacities sustainably and equitably, and develop locally contextualized solutions.

\section{About This Paper}

This paper examines the existing literature on locally led adaptation, looking at efforts that have optimized finance through direct and consistent collaboration with local actors and identifying initiatives that embody locally led principles rather than traditional stakeholder consultation or participation. In line with the Global Commission on Adaptation's Year of Action, the authors sought to identify projects and designs that aim to catalyze accelerated action and support for locally led adaptation. Partners in the commission seek to spur governments and funders to expand the financial resources that are available to local governments, community-based organizations, and other local actors, and help create structures that give local groups greater influence on decision-making over projects that directly affect them (GCA 2019). The primary audience for this paper is funders, international and local institutions, and decisionmakers worldwide who are seeking to understand how to invest in locally led interventions that strengthen resilience, including climate resilience.

Where possible, the paper includes examples of projects or programs that have been responsive to local priorities and produced benefits (whether initial or over time) in terms of climate resilience. The authors synthesized the essential characteristics and program designs of international and country-driven investments that have reached the local level and enabled locally led adaptation. The application of this knowledge could enhance efforts to increase focus on-and finance for-durable, positive changes via locally led adaptation.

\section{Key Findings}

\section{Only a third of the projects (138 of 374)} reviewed contained or documented any locally led elements explicitly, and a much smaller number (22) featured a locally led approach as a core or central component. Local actors are often involved in adaptation interventions as recipients but rarely in decision-making-including about how funding is allocated-or leadership roles throughout project life cycles.

- Barriers to locally led financing include a lack of investment in local capacities to manage funds and adaptation processes; low levels of 
accountability both upwards and downwards; limited amounts of funding making it to the local level; and funding used in a way that does not address or respond to local priorities.

\section{There are a number of important characteris-} tics that enable locally led adaptation:

Institutional and technical capacity building tailored to different contexts, including increasing local capacities to access and manage finance, is closely tied with sustainability and scalability.

Meaningfully including local leadership to tackle climate vulnerabilities requires making substantial changes in how global, national, and private finance is channeled and spent. These changes include incorporating devolved finance mechanisms and increasing financial flexibility in design and disbursement. Flexible funding allows local actors to manage funds in ways that best fit local needs, priorities, and evolving contexts. This flexibility, especially when combined with flexible design and implementation, can make it easier for interventions to address different climate scenarios.

Existing governance and finance mechanisms, networks, federations, and institutions that reach down to local levels can work together and be expanded to achieve economies of scale and sustainable results, rather than starting new mechanisms or institutions. Establishing intergovernmental and public-private mechanisms or alliances can lower the traditionally high transaction costs associated with capacity building, as overlaps in responsibilities and complementary skills are taken advantage of and pave the way for scaling interventions.

Reinforcing and scaling adaptation action requires awareness and coordination from all levels of government. Local authorities play a central role in reinforcing and scaling adaptation, as do civil society actors who help ensure accountability and the flow of information.

Ensuring that policy objectives are clear and linking activities and adaptive management approaches that feature iterative learning from the local to the national level can foster enabling environments, encourage local actors' agency, and set up the institutional networks needed for longterm resilience.

\section{INTRODUCTION}

Communities have been dealing with and adapting to the effects of climate change with varying degrees of support. They and other local actors are frequently the best placed to understand their own priorities and needs, yet they tend to be recipients of distant experts' choices instead of leaders and decision-makers for planning and implementing climate finance (IIED 2020; Restle-Steinert et al. 2019). The dominant climate finance model consists of channeling funding through numerous intermediaries to short-term projects (Soanes et al. 2019). Decisionmaking by local-level actors in climate interventions is often lacking, including decisions regarding how funding is allocated, which can affect projects' efficacy and sustainability (Restle-Steinert et al. 2019).

The rapid and efficient mobilization of local organizations in response to the COVID-19 pandemic has exemplified the potential power-and inclusivity-of locally led initiatives. In identifying good practices and addressing the gaps in the current climate finance systems, locally led adaptation stands out as an area in much need of financial and technical support to strengthen institutions and systems that enable adaptation (Mfitumukiza et al. 2020).

By locally led adaptation, the authors mean climate adaptation in which local communities, communitybased organizations, citizen groups, local government, and local private sector entities at the lowest administrative structure are included as decisionmakers in the interventions that affect them. Locally led adaptation goes beyond stakeholder engagement as it is often practiced today (common with communitybased approaches) and occurs when local actors, who are directly accountable to local people, have agency over adaptation and development paths. By bringing decisionmaking closer to those most affected, this type of action can deliver democratic, equitable, and context-specific solutions, which can address multiple risks and achieve multiple benefits (Mfitumukiza et al. 2020; Dinshaw and McGuinn 2019).

Despite the rising urgency of adapting to climate impacts, especially for the most vulnerable people and nations, finance for adaptation more broadly continues 
to be insufficient. International priorities focused on strengthening community- and local-level climate resilience have been similarly limited. Historically, 75 percent of global climate finance in the Global South has been focused on mitigation (Resch et al. 2017). While adaptation finance rose to a US $\$ 30$ billion annual average in 2017/2018, the United Nations (UN) Environment Programme's The Adaptation Finance Gap Report estimates adaptation costs of $\$ 140$ to $\$ 300$ billion annually, possibly rising to $\$ 280$ to $\$ 500$ annually by 2050 (Olhoff et al. 2016). The need for additional funding and support for resilience and capacity building more broadly is clear (Caravani et al. 2017).

Of the finance that is available, it is unclear how many of those dollars are going to the local level and to what extent these efforts follow locally led principles. That said, there is growing awareness that programs and projects need to do much more to reach local levels and create enabling spaces for local voices, as affirmed by the numerous countries that have signed on to support the Least Developed Countries (LDC) Initiative for Effective Adaptation and Resilience (LIFE-AR) Partnership Compact in 2019. Building an evidence base for locally led adaptation forms part of these efforts (IIED 2020). The literature review carried out for this paper, and the struggle to find documented examples of locally led efforts (versus community consultation and/or participation), further confirms the extent of the progress that still needs to happen and the untapped potential of locally led adaptation. Of all the sources reviewed, only a third (138 of 374) of the interventions documented any locally led elements explicitly, and a much smaller number (22) featured a locally led approach as a core or central component.

Drawing from an extensive literature review, this paper provides an overview of the state of play when it comes to locally led adaptation interventions (both how funds are allocated and how interventions are designed and carried out), illustrating real-world examples, benefits, and challenges. After briefly describing the main actors of the climate finance space and analytic methodology, the authors define locally led adaptation, differentiate it from more traditional stakeholder engagement approaches, and identify from the literature review key characteristics and design trends (like flexible funding and iterative program design) that enable locally led adaptation.

\section{LANDSCAPE OF EXISTING INVESTMENTS THAT COULD BE TAPPED INTO TO ADVANCE LOCALLY LED ADAPTATION}

It is important to understand the current climate finance landscape to identify how different funding entities and processes could help enable and support locally led adaptation. The purpose of this section is to describe the main entities in the climate finance space, including funders and institutions, and how finance flows from the international to the subnational level. The majority of climate and development finance, including for adaptation, is deployed at the international and national levels.

\subsection{Key Actors in Climate Finance}

Climate finance flows to the local level from bilateral and multilateral international funders or funds, from national sources, and from subnational mechanisms. Finance traditionally flows via various intermediaries, like those highlighted below and in Figure 1, before reaching the local level.

Developed country funders or donors, and their individual bilateral institutions, are important actors. For example, in Germany, the Federal Ministry for the Environment, Nature Conservation and Nuclear Safety and the Federal Ministry for Economic Cooperation and Development, among others, give resources to other agencies, such as the German Society for International Cooperation (Deutsche Gesellschaft für Internationale Zusammenarbeit; GIZ), which are not directly funded from Germany's annual budget. In addition to contributing to global funds, bilateral actors have their own programs that emphasize devolved funding.

Government bodies, particularly national governments' development finance institutions, are often in charge of distributing funding from both international funders and their national budgets, which is in turn allocated from the subnational to the district or municipality level. Both the type and structure of this trickle-down process depend on the level of political, administrative, and fiscal decentralization within countries (UNDP et al. 2013). This process is made even more difficult where transfers are untargeted and unconditional. Finance from nonpublic sources may reach local actors in a more direct way through civil society organizations (CSOs). National climate funds can operate with similar external 
and domestic sources as well. Subnational flows include locally generated revenues and at that level can make up a proportion of local funding.

Multilateral climate funds draw funds from various sources (including countries' bilateral development agencies). UN agencies and multinational and regional development banks fall under this category. Adaptationfocused multilateral climate funds include the Global Environment Facility (GEF) and its special trust funds; the Least Developed Countries Fund (LDCF) and Special Climate Change Fund (SCCF); the Adaptation Fund (AF); and Pilot Program for Climate Resilience (PPCR); as well as crosscutting climate funds like the Green Climate Fund (GCF).

The instruments used to deliver on pledges affect the level of risk that funds can tolerate in their portfolios, which in turn affects both their ability to mobilize climate finance at scale and the types of projects that are funded. The LDCF, SCCF, and AF are capitalized solely through grants, giving them great flexibility in the risk profile of their portfolios (Amerasinghe et al. 2017). While the Climate Investment Funds (CIF), GEF, and GCF are also capitalized through grants, some member countries provide contributions as loans or capital (Amerasinghe et al. 2017). The AF, GEF, and GCF are pioneering direct access modality, as well as launching enhanced direct access modalities through country institutions and systems (Amerasinghe et al. 2017).

Nongovernment organizations and the private sector (e.g., international development and microfinance firms) are other key actors. In addition to climate financing in the form of loans, grants, subsidies, credit, or savings products, these institutions sometimes provide financial services for vulnerable communities and people living in poverty.

\section{Figure 1 | Climate Adaptation Finance Flows}

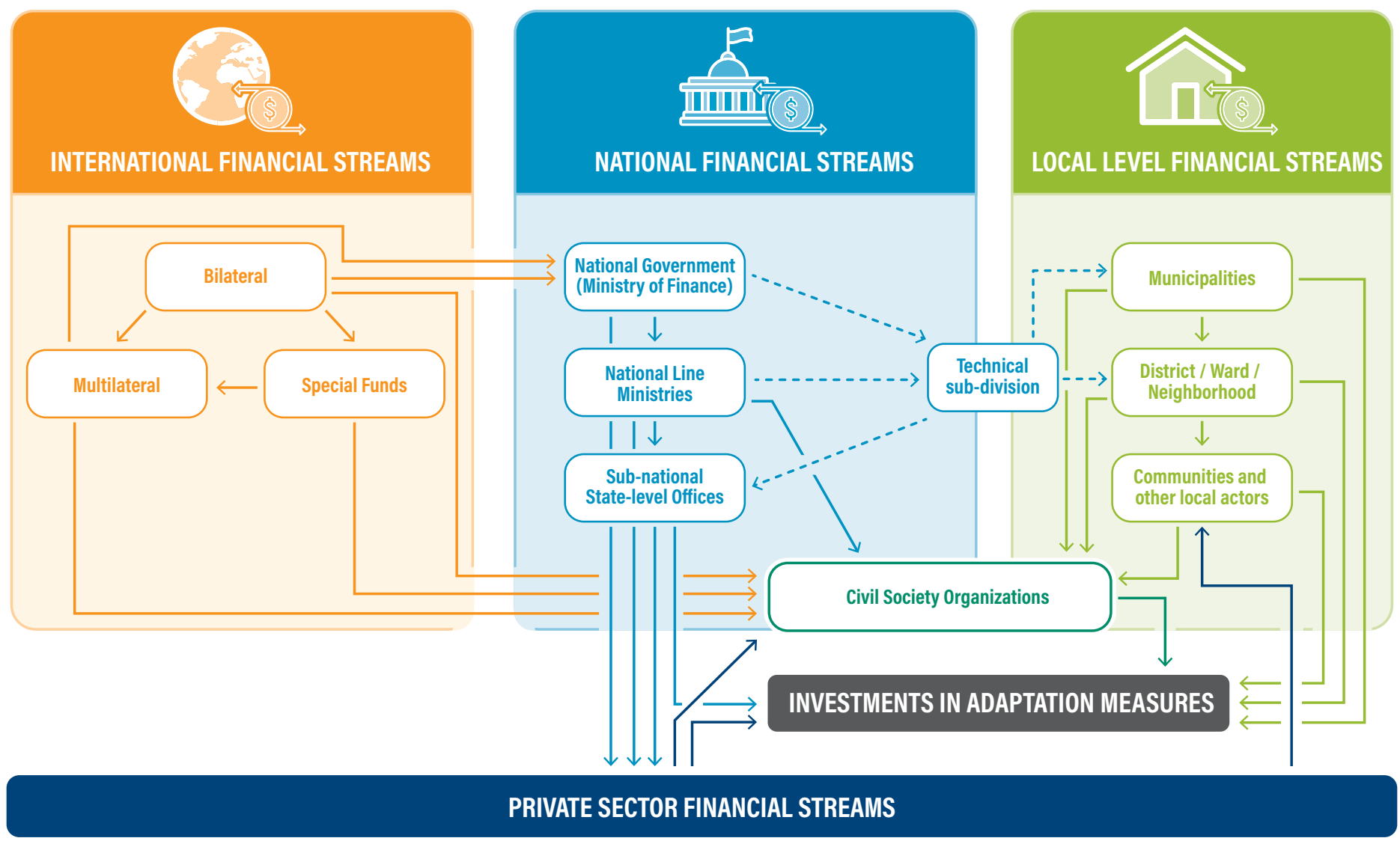




\section{SCOPE AND METHODOLOGY OF THE LITERATURE REVIEW}

This review focuses on interventions in the Global South that aim to strengthen resilience through locally led adaptation, whether in the face of climate impacts, development challenges, or both. In the search for these locally led examples, the authors reviewed over 70 adaptation-focused and community-centered program and project evaluation reports and briefings, funded by global, national, and local climate funds, including government funders and mechanisms that aid in the devolution and decentralization of financing. While this paper's definition of local actors goes beyond communities and includes local governments, local nongovernmental organizations (NGOs), and civil society organizations, most of the literature reviewed focused on the communities and local governments.

Most of the literature was collected through internet searches (in English) in repositories like EBSCO, JSTOR, and Google Scholar, and targeted projects and programs that finance resilience interventions at the subnational level. Key search terms included "community-driven development," "community resilience," "community resilience investments," "devolved finance," "decentralized finance," "locally led," and "local investments." Appendix A provides a detailed look at the types and number of sources and projects reviewed.

In assessing projects to review, the authors focused on evaluations and aggregated assessments and reports written by implementing bodies and independent research institutes of major climate and adaptation funds, which at times comprised dozens of projects (e.g., the four Huairou Commission Community Resilience Fund sources together cover 50 projects). Programs and projects that indicated the inclusion of local agency and leadership, addressed socioeconomic disparities, and/or sought to devolve finances were examined further to assess whether locally led elements were central to their frameworks or designs.

The authors limited their locally led adaptation examples to interventions implemented in the last two decades and literature in which local actors played a decisionmaking role, rather than being just target beneficiaries or engaged in more consultative ways. A project that invited communities to workshops or consultations would not be considered locally led, while one that included local leaders in the project design and implementation committee and accounted for how projects could be sustained after their allocated funding lifetimes would be (see Section 4 for a more in-depth explanation of locally led principles and sample activities).

The sources reviewed cover 374 specific interventions worldwide, of which only a small subset (22) featured a locally led approach as a core or central component for how activities were designed or carried out. Some of these 22 examples are featured throughout the paper, as well as compiled in Appendix B with an explanation of the locally led elements they embody. The authors synthesize the trends and characteristics that were featured most frequently in locally led investments, and what enabled them to scale or lead to longer-term change. Much of the literature was limited when it came to whether locally led adaptation led to more effective, sustainable, and climateresilient outcomes. Likewise, it is important to note that more examples of locally led adaptation efforts likely exist that are self-funded at the subnational or local level and therefore have little or no documented evidence available via online documents.

The review included projects across a range of relevant sectors like agriculture, infrastructure, and housing to understand whether and how they embedded resilience and local leadership. Efforts to identify opportunities to strengthen such elements in their design and implementation were considered as well. The authors reviewed sources from both rural and urban settings to delineate differences and commonalities between these contexts. Over 20 relevant peer-reviewed articles on best approaches for monitoring adaptation and the challenges and barriers of climate finance for locally led resilience were also consulted.

\section{LOCALLY LED ADAPTATION AND HOW IT DIFFERS FROM TRADITIONAL STAKEHOLDER ENGAGEMENT EFFORTS}

Local action to advance climate adaptation shares the principles of traditional community-based adaptation (CBA) and community-driven development (CDD) approaches, yet differs in key ways. CBA is an empowerment-based approach that encourages community-level leadership in assessing, planning, prioritizing resources, implementing, and monitoring adaptation measures through a participatory process (Mfitumukiza et al. 2020). Similarly, programs following CDD approaches are guided by principles of transparency, 
participation, and accountability to enhance the participation of communities, local governments, and other institutions (World Bank 2020). Often targeted to increasing awareness of climate impacts and locally led solutions and capacity building (in the case of CBA) and featuring institutional and technical knowledge improvements (for CDD), these types of interventions acknowledge that poverty and marginalization are major contributors to climate change vulnerability and emphasize the need for capacity building, knowledgesharing, and funding to make their way to communities themselves (ADB 2019).

In locally led adaptation, local actors' leadership and agency are not just encouraged but actively supported at various stages of an intervention's design and execution. Inclusive representation and involvement of local actors occurs in the planning and decision-making process to identify priorities, investments to be made, and who will be involved in different stages (Mfitumukiza 2020; IIED forthcoming). Local knowledge and capacities are trusted and recognized, and diverse participation helps coordinate adaptation actions, avoid duplication, and enhance efficiencies and good practice (IIED forthcoming). Power, rights, and resources from international and national governments are shared with local actors, and local capacities in particular (including enhancing understanding of climate risks) are built with the goal of strengthening leadership and abilities to develop sustainability and decrease the dependencies on systems that increase their vulnerability (IIED 2020). Figure 2 provides an illustrative spectrum of how stakeholder participation and leadership changes across approaches.

Locally led adaptation will not always be the right solution in every situation. Sometimes, strategic action at the national or regional level can have a greater impact on local-level actors than smaller, local initiatives. For example, the Philippines' Disaster Risk Reduction and Management (DRRM) Act of 2010 mandates the creation of DRRM offices in every province, municipality, and city, and that local governments allocate at least 5 percent of their revenues toward disaster reduction and adaptation planning and measures (Tye et al. 2020). This national legislation has led to on-the-ground action like procuring early warning systems and equipment, and establishing quick response funds for relief and recovery (Balala 2019). While the focus of this paper is on locally led adaptation, the authors recognize that multiple approaches-at various levels-are needed.

\section{Figure 2 | Moving from Community Consultation to Locally Led Adaptation Can Be Viewed as a Spectrum}

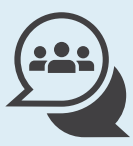

TRADITIONAL COMMUNITY CONSULTATION CAN INCLUDE:

Community members are invited to learn about the intervention to be implemented, e.g. via participation in workshops.

Community largely viewed as beneficiaries. They are consulted and involved in a limited manner.

Community members ultimately don't have tangible power to decide who or what is funded or how projects are executed.

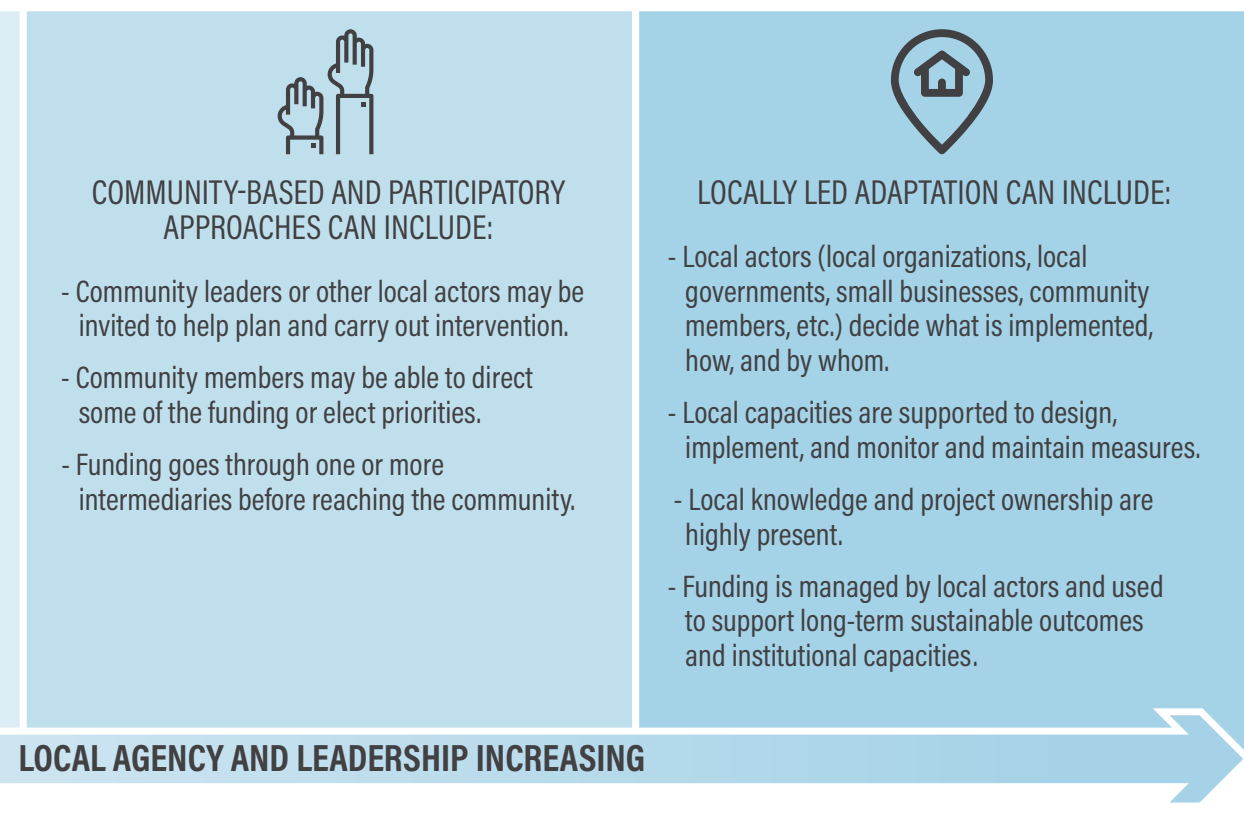

Note: This graphic is not meant to simplify or encompass the very broad variety of approaches that exist, but rather to compare a subset of targeted characteristics to show how locally led action differs from other approaches.

Source: Authors. 
It is also important to note that traditional stakeholder engagement efforts may not challenge or address gender inequality and social exclusion. As such, projects and programs can continue to promote existing social and cultural norms, ethnic or religious discrimination, elite capture by individuals with more resources, and unbalanced power dynamics-such as women's hesitation to voice their opinions in male-dominated groups in many countries.

With adequate considerations to represent and support all vulnerable groups in a given context, locally led processes can enhance equity and social inclusion both for interventions and for the long term. A BRACED (Building Resilience and Adaptation to Climate Extremes and Disasters) project in Mali, for example, highlights the value of ensuring that leaders or champions are chosen by the community to represent them and that they are, more importantly, making decisions (Leavy et al. 2018). In several cases, communities chose leaders based on merit and experience: individuals such as retired civil servants or teachers who are known for their personal experience in local development and/or their vision of development issues. However, program implementers should carefully consider entrenched norms and practices, as in the BRACED-funded Myanmar Alliance initiative (2015-18). During village planning, women "tended to fall into line with the priorities articulated by male leaders" (Leavy et al. 2018). In Nepal, the BRACED Anukulan project (201517) set targets to include at least 52 percent women in total farmers' group membership and in decision-making positions, and multiple projects established women-only Village Savings and Loan Associations (Leavy et al. 2018). The project evaluation notes that women's confidence to speak out in meetings and participate in public affairs increased, creating conditions for women's leadership (Leavy et al. 2018).

\section{COMIMON CHALLENGES OF AND BARRIERS TO LOCALLY LED ADAPTATION}

Based on the literature review, the authors identify several common challenges of and barriers to locally led adaptation. Capacity is one common challenge and barrier. Different local actors across the Global South have varying capacities to access the information, financing structures, and funding they need. Reasons behind funders' reluctance to invest in local actors, institutions, and organizations include external perceptions of risk, high transaction costs, and insufficient subnational capacities of local governments and organizations to develop and carry out projects (IIED 2017). Accessibility also remains a barrier to locally led adaptation because funding is "lost in complex processes" or not adapted to local priorities (Restle-Steinert et al. 2019).

Local actors on the front lines often lack the financial resources and capacity to plan and implement adaptation themselves (Restle-Steinert et al. 2019). Addressing such capacity gaps-both as part of projects and also outside of them, and on a more institutional level-has been identified as critical, and could help make investing in locally led efforts more effective and attractive to funders. Related limitations at the local level can include a lack of awareness of the need and incentives for climate adaptation, limited administration capacities, weak policies, complicated dynamics in local politics, and inappropriate budgetary allocations (IIED et al. 2016; Musah-Surugu et al. 2017). These factors have implications for the extent to which finance reaches local levels-and, most importantly, the extent by which adaptation is led by local actors.

There is also the question of where and how governments and local actors can access additional finance to deliver the required investments in capacity building, which in turn is closely tied to being able to access international and national climate finance. Some solutions identified in the literature include enhancing local capacities and skills as part of funding packages to encourage continuity and long-term sustainability-with regard to management, learning, monitoring, and scaling-after the intervention has ended.

\section{TYPES AND INTERVENTION AREAS OF INVESTMENTS FOR LOCALLY LED ADAPTATION}

This section categorizes the types and intervention areas that featured most frequently in the literature review, where the few examples of locally led adaptation were found. Examples from the 22 locally led adaptation interventions identified in the review are included here to further illustrate what elements of locally led adaptation look like in practice.

The most frequently featured investments associated with strengthening local-level resilience found in the literature review were in the areas of community-based adaptation, community-driven development, and natural 
resource management. These are important to note as areas where the funding and capacity priorities have been directed thus far, which can inform the types of successful adaptation projects that can be scaled and highlight where gaps in investment may remain. Interventions to enhance the resilience of sector services like climate-resilient infrastructure, agriculture, energy systems, and water management were also examined. The authors found that community-level investments engaged local actors to varying degrees, with few being locally led, whereby local actors had decision-making power and leadership with other actors. Frequently, the evaluations included in the review referred to communities as beneficiaries with little to no information on if and how they were engaged and whether or how the interventions were locally led. Modalities for the disbursement of funds in a locally led manner included microfinancing, national budget allocations, new hybrid funding models, communitydriven development, and social protection schemes.

\subsection{Community-Based Adaptation and Community-Driven Development}

Recognizing that local actors are often best able to identify local vulnerabilities and potential solutions, the authors looked into both CBA and CDD as common features in investments made at the community level. While there is widespread recognition of the principles of CBA and CDD, more concerted efforts should be made to ensure that local actors are empowered decision-makers or leaders of change, as opposed to recipients of interventions.

A locally led adaptation example arising from the literature is the Huairou Commission's Community Resilience Fund, which uses a microfinancing modality to make funds available to disaster-prone communities, emphasizing the need to support women by positioning them as community leaders. In some cases, as in Nicaragua, this meant amplifying and scaling existing or semiorganized coalitions. Women were trained to map risks and vulnerabilities in their communities, and these maps were used to identify priorities and appropriate solutions (Rodriguez 2010).

Investments in risk-mapping supported women in sustainably working the land for crop improvement and identified gaps in activities like soil and water conservation practices to prevent erosion and runoff. To ensure that communities could be independent and resilient beyond the project, activities included setting up new income streams, as was the case in Nicaragua where the fund supported the Unión de Cooperativas de Mujeres Productoras Las Brumas, a women's cooperative, in diversifying from coffee, which was becoming increasingly difficult to grow due to the changing climate. Widespread use of three agricultural methods-diversified plots, table gardens, and plant nurseries-reduced the women farmers' economic risks from floods and drought in Jinotega, Nicaragua, and multiplied the average annual net earnings by six times between 2009 to 2014 (Huairou Commission 2016). With the Huairou Commission's training, women from grassroots groups in Guatemala and Honduras were subsequently invited as expert practitioners to collaborate with government ministries and train other women (Rodriguez 2010).

\subsection{Ecosystem-Based Adaptation}

Ecosystem-based Adaptation (EbA) involves using biodiversity and ecosystem services to help people adapt to the adverse effects of climate change (Reid and Alam 2014). It is often integrated with CBA approaches and draws from improved learning from resource management disciplines, such as community-based natural resource management (CBNRM). ${ }^{1}$ As with CBA and CDD, the literature review found that greater efforts can be taken to create spaces for local actors' decision-making and agency, and to voice local and Indigenous groups' knowledge of ecosystems to inform adaptation solutions. Indeed, examples of strong locally led adaptation by Indigenous peoples was a gap in the materials consulted.

EbA is not being widely or consistently implemented, or sufficiently mainstreamed, especially given its potential to increase resilience for the most vulnerable populations whose livelihoods are tied to the ecosystem and/or are reliant on natural resources (Reid 2016). To some extent, this is due to a need for the evidence base for EbA to be strengthened with more robust quantitative evidence, but it is also due to a need to recognize long-existing local knowledge (Black et al. 2016; Reid 2016). However, when managed appropriately, it has the potential for social, economic, and environmental co-benefits and cost efficiencies, and an increase in local resilience and adaptive capacity (Reid 2016). The crosscutting nature of EbA requires the involvement of various partners (including, commonly, conservation NGOs) and government departments working with local communities (Kapos et al. 2019). 
The Climate Action through Landscape Management (CALM) Program (2019-2024), financed by the World Bank and implemented by the government of Ethiopia, is one initiative that employs a participatory approach with strong locally led characteristics. Community members are brought together at the micro-watershed level to create local Watershed Teams to prepare and implement Watershed Management Plans (World Bank n.d.). These teams are made up of the local chairman, an official from local government, male and female representatives or leaders of each community representing different social groups, respected community members, religious leaders, youth representatives, and others (such as innovative farmers) proposed by the community (World Bank n.d.). These are decision-making, priority-setting positions that are also representative of the communities themselves, thus promoting social inclusion and local agency. The CALM Program is a model that seeks to bridge critical capacity gaps and support locally led adaptation in other ways by embedding local institutions in a broader institutional and policy framework and across sectors. This can enable the sustainable restoration of degraded landscapes, secure land tenure, and consolidate natural resource management gains for the long term via institutional reforms (World Bank 2019).

\subsection{Resilient Community Infrastructure}

With a few notable exceptions, the authors observed that the majority of the local-level infrastructure interventions found in the review featured local actors as beneficiaries, not as decision-makers. These investments often involve community-based organizations in partnership with local governments (ADB 2019). An impact evaluation of CDD programs shows that community involvement often made substantial contributions to improving the quantity and quality of small-scale infrastructure (ADB 2019).

Two projects stand out for their locally led elements. The first was a project led by the Women's Union in Da Nang, Vietnam, which enabled local community grassroots groups to set their own investment incentives. This union developed and piloted incentives for investments in stormresistant housing suitable for a low-income, typically female-led housing market. With the support of the Institute for Social and Environmental Transition (ISET), the revolving credit and technical support upgraded 425 storm-resistant houses, all of which survived Typhoon Nari in 2013 (Archer et al. 2017).
The second is the Tajikistan Climate Resilience Financing Facility (CLIMADAPT) credit line, which has supported over 3,000 sub-projects since 2016, with approximately 58 percent of sub-loans being used for energy efficiency investments and 39 percent for water efficiency investments (CIF 2018). The credit line sought to make the Tajik private sector more resilient, offering loans to small businesses, farmers, and households through local financial institutions. Resilience-building technology and measures were vetted and listed by CLIMADAPT, but it was the communities and individuals themselves who decided on a specific adaptation measure based on whether the solution was responsive and appropriate for their needs and livelihoods. These investments save in the region of 50 gigawatt-hours per year of primary energy and 13 million cubic meters of water annually, and prevent soil erosion estimated to be around 695 tons per year (CIF 2018).

\subsection{Social Protection Instruments and Systems}

In the literature reviewed, the design and implementation of social protection agendas rarely featured locally led approaches. This is despite the fact that countries disproportionately affected by climate change are investing over $\$ 500$ billion each year in social protection instruments and systems-in the form of conditional and unconditional cash transfers, public works programs, pensions, school feeding programs, and increased capacity of social protection systems to respond after disasters (Agrawal et al. 2019). When developing social protection agendas for adaptation, policymakers are not yet tackling the structural causes of climate vulnerability, inequality, and marginalization, or leveraging rights-based approaches-which include principles for participation and inclusion (Tenzing 2020).

One example of an intervention with locally led elements is the Horn of Africa Risk Transfer for Adaptation (HARITA) program by Oxfam and the Ethiopian government, which ran from 2009 to 2012 and sought to design an affordable weather-indexed insurance package for smallholder farmers facing drought. HARITA actively and collaboratively engaged locals in designing and implementing measures to prevent soil erosion and rainfall runoff and undertake small-scale irrigation works (Madajewicz et al. 2013). Until that point, drought insurance for the farmers living in deeper poverty had not been effective due to its high administrative costs and premiums. In HARITA's conversations with farmers, the 
farmers themselves suggested an innovative alternative to paying for insurance with cash: farmer labor. This led to the development of an "insurance-for-work" program, which was paired with an existing government of Ethiopia "food-and-cash-for-work" program, thus expanding insurance access to many more farmers. In 2012, 93 percent of farmers paid with labor in the villages that offered this option; in 2016, insurance had been sold to 18,00o households, and has been linked to increased credit access (Madajewicz et al. 2013).

\section{INVESTMENT CHARACTERISTICS AND DESIGN TRENDS THAT ENABLE LOCALLY LED ADAPTATION}

The literature review reveals that funds that can be used to finance locally led adaptation interventions encourage flexible and adaptive approaches, leverage capacity building for sustainability, and reinforce actions across scales and programs. This section discusses these trends and their potential to enable locally led adaptation.

\subsection{Funding That Is Flexible and Program Designs That Are Iterative Can Significantly Contribute to the Longer-Term Sustainability of Interventions}

\subsubsection{Flexible funding}

The authors found that flexible funding enables locally led adaptation because it allows local actors to control funds in ways that best fit local needs, priorities, and evolving contexts. If funding is flexible, then interventions can address a range of climate scenarios that may play out and local priorities as they evolve or change, despite funders and implementers having their own set of processes, approaches, preconceived notions of what local actors need, and targets associated with disbursing funds.

Funding can be flexible in different ways. It can mean having unallocated, rapid response funds that can be deployed for needs that arise unexpectedly yet are still aligned with the general objectives of the program. In other cases, it is funding that can be disbursed without being earmarked for specific activities and used to leverage additional funding. For instance, grassroots women's organizations in Indonesia, the Philippines, and Vietnam, with support from the Huairou Commission and the Asian Development Bank, were able to leverage flexible funding to acquire additional funds that were used to expand resilient development efforts (ADB 2017). These groups were able to channel subsequent funds raised toward good disaster-resilience practices, like creating community-managed revolving funds to restore livelihoods after natural disasters (e.g., as happened in the Philippines with Typhoon Haiyan) and integrating community priorities into districts' annual plans and budgets (e.g., after Vietnamese rice paddy farmers lobbied for flood protections). The women's organizations were also able to negotiate with local governments to secure both government finance and support to scale up their work.

Another example is the Decentralising Climate Funds (DCF), an action-research and advocacy project that supported communities in Senegal, Mali, Kenya, and Tanzania, implemented by the International Institute for Environment and Development (IIED) and a range of partners (IIED et al. 2017). DCF trialed a practical decentralized funding model in four countries that flexibly allocated 90 percent of each fund to investments prioritized by communities and local authorities, with the remaining going toward management (Hesse 2016). In this model, local and national governments piloted local adaptation funds, where money was planned and budgeted in partnership with communities via committees (Hesse 2016).

Sometimes finance can be flexible because it can be programmed with a great deal of autonomy by the recipient. However, this could entail certain conditions that need to be met or goals that need to be achieved to ensure transparency and efficacy. For example, Kenya's County Climate Change Funds in five counties empowered local government leaders to identify their communities' priorities and to participate in the design and management of investments, and is now being implemented nationally (see Box 1).

IIED's "frontier funds" are a novel approach that channels climate funds directly to highly vulnerable groups, so local actors can access resources without having to go through intermediaries. They are also based on the principles of subsidiary, community agency, and rights (Soanes et al. 2019). The Urban Poor Fund International (UPFI) is another example of providing streamlined access to capital. UPFI aims to enable people living in urban poverty to design and co-manage their own development 


\section{Box 1 Devolved Finance Outcomes in Kenya}

The Kenya County Climate Change Fund (CCCF) mechanism was first piloted in rural Isiolo County from 2011 to 2013 and then scaled to an additional four counties that were highly vulnerable to climate change (Garissa, Kitui, Makueni, and Wajir; see Figure B1.1). Its objective was to improve climate finance flows to newly formed county governments, while empowering local communities via public participation in the design and use of these funds. The first pilot showed that, when financially and technically prepared, local governments can identify and manage investments that meet both local and adaptation priorities. The mechanism was further refined by the Ada Consortium to establish local adaptation planning committees, adaptation planning tools to integrate climate into county plans and legislation, and a monitoring and evaluating (M\&E) system. Kenya's new county governments were able to fully learn and incorporate the CCCF mechanism. Key achievements across the five counties include the following:

- Each county enacted laws committing 1-2 percent of their development budgets to the implementation of priority climate change interventions.

- Better coordination, participation, and efficiency in doing climate change work-like resilience planning tools, climate information systems, and vulnerability and capability assessments-was achieved, leading to more sustainable adaptation.
- Lessons on linking adaptation and development were learned.

- An M\&E system was built to track how adaptation is building resilience and strengthening economic development.

- Implementation of more than 100 community-prioritized public goods investments directly benefited over 500,000 people. A 2018 household survey of Isiolo, Makueni, and Wajir Counties reported that respondents had gained 100 percent more access to water, a savings of two hours each day per household collecting water, an 8 percent increase in annual income, and a cascade of other direct and indirect benefits for livelihoods, food security, reduced household and community conflict, and saved time for women.

Through the CCCF mechanism, Makueni and Wajir Counties have made strong progress in integrating adaptation. Moreover, county- and wardlevel planners have been able to mainstream climate risks into county-level development plans and to prioritize adaptation measures in these plans (Chaudhury et al. 2020).

The Kenyan government is now expanding and institutionalizing the approach nationwide via the National Climate Change Action Plan (20182022). This scale-out is funded by the Republic of Kenya, the Embassy of Sweden, the United Kingdom, and the World Bank.

FIGURE B1.1. | COUNTIES WHERE KENYAN CLIMATE CHANGE FUNDS WERE PIONEERED

\section{KENYA}

Source: Crick et al. 2019. Figure: WRI. 
agendas, recognizing that vulnerable and resourcescarce communities often face institutional barriers to obtaining initial funds for adaptation. UPFI, as a subsidiary of Shack/Slum Dwellers International, provides communities with direct control of an initial amount of capital, which gives them some leverage to negotiate with formal bodies like banks and government for housing and infrastructure-financing projects in India and South Africa (Walnycki 2015; Schermbrucker et al. 2016).

\subsubsection{Flexible design and implementation}

Another trend observed by the authors was that flexible design and implementation gives local actors the ability to identify and finalize outputs and activities in a way that fosters greater learning and adjustment. One aspect of flexible design can be developing activities as a rolling process. Activities in the first stage of the intervention would be nearing completion before the next stage and group of activities was finalized, thereby enabling local actors to adjust the programming to better suit their previously identified priorities or to fit new priorities (as would have been the case if a project was underway during the initial COVID-19 outbreak).

Even if interventions are not implemented on a rolling basis, incorporating flexibility into the design and implementation allows for iterative learning and adaptive management, which can significantly contribute to the sustainability of results. Adaptive management permits making adjustments in activities in the face of climate and non-climate uncertainties. This allows interventions and programs to improve over time with learning and new knowledge, especially in long-term, multiyear commitments with year-to-year allocations.

The Ada Consortium (a group of international and Kenyan partners that supports county governments in integrating climate change into development and planning) acknowledges that having "an extended, flexible design process during which the shape of the program can evolve through 'learning by doing' is vital. Iterative learning, based on evidence and critical, participatory reflection, is a key means for tackling 'wicked' problems" (Crick et al. 2019).

\subsection{Institutional and Technical Capacity Building, Including the Capacity to Access and Manage Finance, Is a Main Feature of Locally Led Projects \\ 7.2.1 Establishing tailored capacity building across contexts}

The authors found that capacity building becomes a feature either by design-where capacity is a core activity and a key outcome of the program-or as a support/ by-product of the intervention. The theory of change ${ }^{2}$ behind its inclusion in the design phase is that increased capacity would allow local actors to directly identify their priorities, pursue additional or future streams of funding, and manage and implement interventions. In short, strong local capacity is a key factor in building resilience while addressing underlying drivers of multidimensional poverty and empowering vulnerable communities (Mfitumukiza et al. 2020). If capacity building is the goal of a program, a wide array of capacity building is neededfor instance, to collaboratively identify climate risks and vulnerabilities; access information and resources; and plan for and carry out adaptation measures, monitor their effectiveness, and take corrective measures as needed.

One reoccurring aspect of capacity building that surfaced in the literature and project evaluations is the need for investments to help improve local actors' capacities to access and manage climate and non-climate finance (e.g., Caravani et al. 2017; Mfitumukiza et al. 2020). Several project and fund assessments reviewed by the authors show that accessing and managing finance requires the support of national governments in engaging the local actors themselves in the identification and mapping of needs and vulnerabilities, as well as in deciding what type of finance is needed for adaptation interventions.

The type of funding, associated risks, and level of technical literacy can differ greatly across regions, landscapes, and socioeconomic contexts. Some of these differences and challenges can be illustrated by differences in local capacities in an urban versus rural setting. Depending on their ratings and starting positions, city governments and institutions can benefit from their creditworthiness and financial management history to attract more (and better) investments, compared with their rural counterparts (Floater et al. 2018). City governments have more options 
for shifting their financial maturity and debt credit arrangements to leverage the availability of funds (Floater et al. 2018). Similarly, city governments also tend to be at an advantage when it comes to being aware of adaptation and financing mechanisms. Indeed, climate funds are increasingly targeting cities, though the majority are going toward mitigation and not adaptation interventions (Barnard 2015).

\subsubsection{Supporting institutional change}

The authors found that investing in local institutions can also result in key partnerships with government, the private sector, and others to develop complementary approaches to tackle long-term issues like climate change. Adaptation occurs within an institutional context that includes such public institutions (such as local

\section{Box 2 | Locally Led Resilience Outcomes from Multilateral Funds}

\section{Global Environment Facility's Small Grants Programme}

The Global Environment Facility (GEF) Small Grants Programme (SGP), created in 1992, seeks to address communities' livelihood challenges while reducing environmental threats. It provides direct and continuous technical and financial support to local civil society organizations (CSOs) and communities through modest grants given based on the idea that once a community-driven idea has been proven, it will be easier to scale up through local networks and partner organizations. ${ }^{\circledR}$ The program has been allocated $\$ 288.28$ million and over 125 countries have received grants, where the maximum amount for each grant is $\$ 50,000$ and the average is $\$ 25,000$. Interestingly, each SGP country program has followed a unique, nonlinear path that adapts to the local and national context.

Hundreds of micro-projects aiming to empower local CSOs and community-based organizations have been funded. ${ }^{b}$ An independent evaluation, covering the period from 2008 to 2014 and 144 of these projects, found that the program resulted in substantial benefits at the community level:

- Eighty-five percent of the projects sampled by the evaluation had helped improve livelihoods, often in parallel with global environmental benefits

- Direct and indirect benefits with respect to gender were apparent in over half of the 103 projects assessed for gender. Benefits include better access to microcredit, water, and energy; greater incomes and time savings (e.g., less time fetching water); and women's empowerment, evident in women taking up new leadership and decision-making roles in projects and community activities.

- Replication and scaling up of activities occurred organically at nearby sites, despite that not being a specific part of the program's strategy, in the majority of projects.

- Mainstreaming project activities more broadly is also evident, for example, in influencing policy.

\section{United Nations Capital Development Fund's Local Climate Adaptive Living Facility}

The Local Climate Adaptive Living (LOCAL) Facility is a United Nations Capital Development Fund (UNCDF) global program that delivers grants and technical assistance to subnational governments in Africa, Asia, and the Pacific. Today, it engages with 107 local governments in 14 Least Developed Countries. The facility delivered nearly $\$ 17$ million through grants and technical assistance in 2014-18 and mobilized close to $\$ 60$ million from parallel sources. Its goal is to increase local climate awareness and capacities, integrate adaptation into local government processes, and raise the financing available to these governments. Outcomes from the 2014-18 period include the following:

- The number of local authorities engaged in the program has increased by 39 percent, representing over six million people.

- Bhutan is now scaling the mechanism to 100 local governments by 2020. Similarly, Cambodia has secured funding to scale climate adaptation investments in 32 districts.

- Five countries (Benin, Bhutan, Cambodia, Mali, and Tanzania) have been nominated as national implementing entities for Green Climate Fund accreditation; four have submitted concept notes.

- Progress has been achieved in countries' capacities to conduct climate risk assessments and pilot new methods.

In Tuvalu, LoCAL was designed as a full-scale mechanism for local government financing in accord with the country's decentralization policy; it developed synergies with the National Adaptation Programme of Action (NAPA) II and the Public Service Reform Program to coordinate support on vulnerability assessments, strategic adaptation planning, and staff organizational development. Change was perceived as a "direct result" of the design of activities to be implemented together in packages to be mutually reinforcing and complementary. 
governments), private institutions (such as businesses), and civil society organizations (such as cooperatives). Often, institutions at the local level in the Global South do not have all the resources they need to operate outside of narrowly defined projects, making it difficult to plan for the long-term impacts of climate change. Investing in local-level institutions can enable long-term adaptation and support the evolution of these institutions according to community needs, facilitate project continuity, and build trust with the community.

With its three-year grants, BRACED has supported 120 organizations across 13 countries in becoming more climate resilient. Its approach recognizes that supporting institutional changes is instrumental in forming the necessary context for greater adaptive capacities to thrive and bringing about scale and transformation (Leavy et al. 2018). BRACED embedded climate risk within local planning, strengthened local organizations' capacities to implement resilience activities (like early warning systems), and facilitated land tenure and resource use agreements (Leavy et al. 2018). Outcomes reflected at the individual, household, and systems levels in communities involved with BRACED include the following:

Improved and diversified incomes-for example, in six districts in Nepal, the Anukulan project (2015-17) increased the incomes of half a million people and raised the percentage of households above the poverty line from 38 percent to 57 percent

Improved food security-for example, the above Anukulan project in Nepal led to a dietary diversity increase from 50 percent to 76 percent

Better access to water and improvements to agriculture-for example, the Anukulan project led to daily savings of four hours of work for women

Increased access to financial services and to climate risk information-for example, the Myanmar Alliance initiative (2015-18) grew village savings and loans by almost 500 percent in 155 villages in Myanmar (Leavy et al. 2018); regarding climate information, national and subnational actors were convened to interpret, communicate, and act on weather forecasts (Leavy et al. 2018)

Successful pilot projects can lead to scaling in other locations, yet this scaling depends in part on the existence of enabling policies and structures at the national level. Institutional structures at the national level, like decentralized funding mechanisms dedicated to climate adaptation, can create more predictable and long-term funding for adaptation, decreasing reliance on donor funding, and helping to align with and complement other programs that intersect with adaptation.

Decentralization is one kind of institutional shift that enables locally led adaptation at scale (Mfitumukiza et al. 2020). Uganda decentralized its water resource management to four zones based on natural catchment basins, establishing different governance structures (including forums and committees) and activities that are all stakeholder-driven (LIFE-AR 2019). The structures were formed following a study that found that "water resource planning and management was most effective when conducted at the lowest appropriate level and based on hydrological catchments" (LIFE-AR 2019).

\subsubsection{Creating, maintaining, and expanding local coalitions to access additional financing to scale locally led adaptation}

The authors noticed a trend in the literature showing that setting up alliances or mechanisms between governmental and nongovernmental bodies to assist communities in accessing finance, as IIED did in Kenya, Tanzania, Mali, and Senegal, can increase communities' capacities to draft viable proposals. The Adaptation Fund's Community Adaptation Small Grants Facility project, which benefited 12 small grant recipients in South Africa, identified capacity building as essential for success and so set up regional Facilitating Agencies to assist local organizations in improving their institutional and technical capacities for record keeping, financial management, and climate adaptation (Lorimer 2019). Where it makes sense, intergovernmental and public-private mechanisms can lower the traditionally high transaction costs associated with capacity building, as overlaps in responsibilities and complementary skills are capitalized upon. The success of such initiatives can also help pave the way to expand efforts to other regions or levels of government (as illustrated by Kenya scaling efforts to the national level discussed in Box 1).

GIZ also recognizes two main approaches to strengthening local actors-both of which involve capacity building: capacity building for local-level representatives and organizations; and grouping local entities and strengthening their networks. These approaches are echoed by several funders such as GCF and Adaptation 
Fund and reflected in many projects and initiatives (Restle-Steinert et al. 2019). Long-standing relationships built on trust and combined knowledge and experience can be key factors for coalitions to work well. This was certainly the case for South America's Gran Chaco communities, which-over three decades of collaboration and despite large geographic distances-have built a very effective early warning system and risk maps to anticipate floods and therefore prevent deaths and property damage (Avina Foundation 2017).

\subsection{Reinforcement across Levels of Government and Linking Packages and Programs}

Several sources in the literature review indicate that scaling down clear policy objectives to lower administrative levels and linking activities from the community to the national level can help foster muchneeded enabling contexts and incentives which can in turn lead to greater institutional connectivity and positive behavioral change at the local level (Restle-Steinert et al. 2019). A range of civil society actors with climate, finance, and budgeting skills should be involved in processes to ensure accountability and improve the flow of information down to local-level institutions and actors (IBP and UNDP 2018). However, few local organizations have all of these capacities, requiring cooperation or initial short-term investments in capacity training; once these skills are learned, they can become a catalyst for ongoing work (IBP and UNDP 2018). Collaborating with different government institutions, CSOs (including NGOs), the private sector, and international agencies can help build the necessary knowledge and skills to sustainably establish community-level resilience. Furthermore, linkages can maximize actors' strengths and push policy that can bring about systemic change (e.g., UNDP 2010).

The UN's LoCAL Facility, which supports dozens of local governments and climate adaptation activities in 14 countries, demonstrates its potential for enabling climate adaptation investment at the local level (De Coninck et al. 2018; see also Box 2). However, the facility recognizes that local authorities and actors have "unique local-level opportunities and potential to work across sectors and to bundle activities" (De Coninck et al. 2018).
Cementing coordination across sectors and institutions increases effectiveness and primes institutional networks that are key to long-term resilience and catalyzing transformative change.

\section{CONCLUSION}

While evidence of locally led adaptation is still nascent, the examples found in this literature review begin to paint a portrait of the positive role that locally led adaptation can play in interventions, and what it looks like in practice. Wider applications of the following characteristics could help accelerate its uptake and build up the evidence base for its use.

From an investment perspective, institutional and technical capacity building and flexible funding and program design are two areas that can deliver high and durable returns with far-reaching outcomes, especially when linked to community leadership and decision-making (LIFE-AR 2019; Soanes et al. 2019; IIED 2020). Flexible funding can enable communities and local actors to control funds in ways that best fit their needs, priorities, and evolving contexts. In addition, flexible funding can be leveraged to demonstrate and scale up efforts to attract greater support and resources (as evidenced by the Kenya County Climate Change Funds scaling nationally, the GEF Small Grants Programme, and other examples cited in this paper).

Adaptive management-an approach for flexible program design-allows interventions to withstand current and future uncertainties (including different climate scenarios), enhancing local actors' long-term resilience in yet another way. Similar to flexible funding, encouraging local decision-making and leadership as part of the adaptive management approach can help ensure that local priorities, needs, and solutions are at the front and center of interventions (Mfitumukiza et al. 2020). Iterative learning in locally led adaptation across organizations and funders, as well as between projects, can lead to improvements in the shaping of programs and further expand capacity building and local knowledge (IIED forthcoming). 
Meaningfully including local perspectives and local leadership to tackle root causes of vulnerabilities to climate change requires substantial changes in how global, national, and private finance is channeled and spent. This includes identifying context-specific decentralized financing mechanisms and de-risking policies and instruments or creating innovative new architectures for delivery-from planning and implementation to funding design and disbursement (IIED 2017; Hesse 2016; Fairman et al. 2020).

Existing governance and finance mechanisms, networks, federations, and institutions that reach down to local levels can work together to reform, build into, and expand the existing landscape of climate adaptation interventions to achieve economies of scale and sustainable results, rather than start new mechanisms or institutions.

Likewise, establishing intergovernmental and public-private mechanisms or alliances can lower the traditionally high transaction costs associated with capacity building, as overlaps in responsibilities and complementary skills are taken advantage of and pave the way for scaling (GEF and UNDP 2020; IIED forthcoming).

Finally, greater collaboration and policy coherence also foster the creation of enabling contexts that can result in sustainability and scalability. Designing local-to-national-level activities as packages allows for more inter-institutional collaboration (Leavy et al. 2018).

Further practice and research are needed to capture and assess the benefits of locally led adaptation. Prioritizing the role of local actors in designing, implementing, monitoring, and evaluating interventions can help ensure that those actors' priorities and needs are met. Investments that focus on such efforts and capacities and address barriers and challenges can go a long way in developing the context-specific solutions local actors need to adapt to a changing climate. 


\section{APPENDIX A: ADDITIONAL INFORMATION ON THE SOURCES REVIEWED}

In the search for locally led examples to enhance community resilience, the authors reviewed over 70 evaluation reports, program and project reports, and briefings of community-centered interventions, funded by global, national, and local climate funds, including government funders and mechanisms that aid in the devolution and decentralization of financing. These sources were complemented by more than 20 relevant peer-reviewed articles on best approaches for monitoring adaptation, and on the limitations of climate finance for locally led resilience. Partners of the Global Commission on Adaptation's Locally Led Action Track also suggested materials to consult.
Table A1 shows the number of projects and sources (by funder or implementing entity) examined in the literature review. Note that some sources originate from the same organization; for example, the authors consulted multiple documents by IIED and BRACED. Although the authors took care to avoid double-counting projects, it is possible that a small number of projects are repeating. Only the sources cited for this paper are in the References (i.e. not all of the 71 listed in the following table).

Table A1 | Number of Projects and Sources Examined by Type of Funder or Implementing Entity

FUNDER OR IMPLEMENTING ENTITY

ACT Alliance

Action on Climate Today

Adaptation Fund

Alternative Energy Promotion Centre (AEPC)

Asian Cities Climate Change Resilience Network (ACCCRN)

Asian Development Bank (ADB)

Asian Sustainable Transport and Urban Development (ASTUD)

International Development Research Centre (IDRC)'s Adaptation at Scale in Semi-Arid Regions (ASSAR) consortium

Association of the Interstate Movement of the Babussu Coconut Breakers (MIQCB)

Avina Foundation and partners (Gran Chaco Proadapt)

Bangladesh Local Disaster Risk Reduction Fund (LDRRF)

Building Resilience and Adaptation to Climate Extremes and Disasters (BRACED)
SOURCES EXAMINED

PROJECTS REVIEWED

2

6

12

1

15

7

1

2

1

$1 \quad 8$

1

6
1

5

15 
Table A1 | Number of Projects and Sources Examined by Type of Funder or Implementing Entity (Cont.)

\begin{tabular}{|c|c|c|}
\hline FUNDER OR IMPLEMENTING ENTITY & $\begin{array}{l}\text { SOURCES } \\
\text { EXAMINED }\end{array}$ & $\begin{array}{l}\text { PROJECTS } \\
\text { REVIEWED }\end{array}$ \\
\hline Climate Investment Funds (CIF) & 3 & 23 \\
\hline Clean Technology Fund (CTF) & 2 & 1 \\
\hline Climate Action through Landscape Management (CALM) & 2 & 1 \\
\hline Dema Fund & 1 & 4 \\
\hline Green Climate Fund (GCF) & 4 & 35 \\
\hline Global Environment Facility (GEF) & 5 & 8 \\
\hline Global Energy Transfer Feed-In Tariffs (GET FiT) & 1 & 1 \\
\hline Horn of Africa Risk Transfer for Adaptation (HARITA) & 1 & 1 \\
\hline Huairou Commission Community Resilience Fund & 4 & 50 \\
\hline Infrastructure Development Company Limited (IDCOL) & 1 & 1 \\
\hline International Development Association (IDA) & 1 & 6 \\
\hline International Union for Conservation of Nature (IUCN) & 2 & 12 \\
\hline Kenya County Climate Change Fund (CCCF) & 3 & 5 \\
\hline LDC Initiative for Effective Adaptation and Resilience (LIFE-AR) & 2 & 95 \\
\hline Local Climate Adaptive Living Facility (LoCAL) & 4 & 14 \\
\hline Nepal Community Disaster Resilience Fund (CDRF) & 1 & 1 \\
\hline Oxfam International & 1 & 3 \\
\hline Pilot Program for Climate Resilience (PPCR) & 2 & 6 \\
\hline Special Climate Change Fund (SCCF) & 2 & 1 \\
\hline UN Capital Development Fund (UNCDF) & 2 & 4 \\
\hline UN Development Programme (UNDP) & 2 & 11 \\
\hline Urban Poor Fund International (UPFI) & 2 & 16 \\
\hline Total & 71 & 374 \\
\hline
\end{tabular}

Source: Authors. 


\section{APPENDIX B: COMPILATION OFTHE LOCALLY LED PROJECTS AND PROGRAMS CITED IN THIS PAPER}

Projects were considered to be locally led if most or all of the criteria discussed in Section 4 were present at different stages of the process and when adaptive or socioeconomic benefits were recorded in the literature. The strength of these locally led characteristics differ greatly by project and stage.

Even though the literature review was as exhaustive as possible, only a small subset (22) of interventions strongly featured these locally led elements, although many of them fell toward the more locally led part of the Figure 2 spectrum with community-based solutions or participatory planning and implementation being a common feature. In many of these cases, the authors found that communities' and/or their representatives' control over funding allocation was often the differentiator in considering projects to be strongly locally led; some of the best documented of those projects, included as examples throughout this paper, are found below. Nevertheless, it is important to note that more examples likely exist; for example, interventions that are self-funded at the subnational or local level and have little or no documented evidence. Table B1 compiles the examples included in the body of this paper.

Table B1 | List of Locally Led Projects and Programs Cited in This Paper

\begin{tabular}{|c|c|c|}
\hline INTERVENTION OR FUND NAME & LOCATION & BRIEF DESCRIPTION \\
\hline $\begin{array}{l}\text { Building Resilience and } \\
\text { Adaptation to Climate } \\
\text { Extremes and Disasters } \\
\text { (BRACED) Anukulan project, } \\
\text { 2015-17, extended 2018-19 }\end{array}$ & Nepal & $\begin{array}{l}\text { A UK Aid Direct (UKAID)-funded project that } \\
\text { facilitated public-private partnerships for the } \\
\text { development of sustainable rural organizations } \\
\text { around economic opportunities in climate-resilient } \\
\text { agriculture, water resource management, and } \\
\text { community forestry. It promoted the harmonization } \\
\text { of disaster risk reduction planning and climate } \\
\text { change adaptation strategies to influence climate } \\
\text { risk management policies and institutions. }{ }^{\text {a }}\end{array}$ \\
\hline
\end{tabular}

Climate Action through

Landscape Management

(CALM) Program, 2019-2024

\section{Ethiopia}

ia

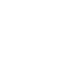

to

\section{LOCALLY LED CHARACTERISTICS}

The project ensured coordination and capacity building between and among the district, municipality, and provincial levels of stakeholders involved. Control of funds given to women forced their agency to take on leading roles in rural institutions and contributed to economic opportunities through public-private partnerships. The project was designed to scale up and integrate proven approaches to strengthen climate change resilience for people in poverty and vulnerable households and communities. ${ }^{b}$

The initiative employs a participatory approach with strong locally led characteristics. For example, the teams involved are made up of the local chairman, an official from the local government, male and female representatives or leaders of each community representing different social groups, respected community members, religious leaders, youth representatives, and others (such as innovative farmers) proposed by the community. ${ }^{d}$ 


\section{INTERVENTION OR FUND NAME}

Decentralising Climate Funds (DCF), 2013-19

(D)

\section{Gran Chaco Proadapt,} 2015-Present
LOCATION

Senegal, Mali, Kenya, and Tanzania

\section{BRIEF DESCRIPTION}

Decentralising Climate Funds was an actionresearch project through which local governments established devolved Climate Adaptation Funds in four Global South countries. The funds were used for investing at the local level and building sustainable and climate-resilient livelihoods for communities. The work, led by the International Institute for Environment and Development, was part of a wider program to devolve climate finance to the local level.e

\section{LOCALLY LED CHARACTERISTICS}

The process of devolving finance involved integrating flexible, local, and often customary planning with formal planning and budgeting processes to create informed and inclusive governance processes. The fund flexibly allocated $90 \%$ of each fund to public-good investments prioritized by communities and local authorities, with the remaining going toward management. In this model, local and national governments piloted local adaptation funds, where money was planned and budgeted in partnership with communities through committees.

Due to years of trust-building and collaboration, community networks in the Gran Chaco region are well-coordinated and use consensus to decide which large-scale initiatives to engage in, and how. The Proadapt project is based on a collaborative, bottom-up organization model with local groups and communities coordinating with local authorities at its center. For example, local leaders were trained to understand and develop flood risk maps, and rising waters are monitored and controlled through participative, real-time tracking to complement satellite data. ${ }^{9}$ The agency of women is also actively promoted and supported, and women continue to gain more decision-making power over time.

HARITA actively and collaboratively engaged communities in designing and implementing measures to prevent soil erosion and rainfall runoff and undertake small-scale irrigation work. The model was participatory in design and focused on capacity building to ensure sustainability and scalability of the project. Farmers themselves suggested an innovative alternative to paying for insurance with cash that led to the development of an "insurance-for-work" program that was paired with an existing "food-and-cash-for-work" program, thus expanding insurance access to many more farmers. In 2012, 93\% of farmers paid with labor in the villages that offered this option; by 2016, insurance had been sold to 18,000 households, and has been linked to an increased access to credit. ${ }^{i}$ 
Table B1 | List of Locally Led Projects and Programs Cited in This Paper (Cont.)

\section{INTERVENTION OR FUND NAME}

Huairou Commission's

Community Resilience Fund

(CRF), 2011-Present

\section{LOCATION}

Guatemala

and

Honduras

Jinotega,

Nicaragua

\section{BRIEF DESCRIPTION}

The CRF is a mechanism that channels funds (ranging from $\$ 8,000$ to $\$ 40,000$ ) to grassroots women's groups, allowing them to identify priorities, demonstrate disaster resilience practices, and collaborate with governments to scale up and strengthen solutions. With funding from the Norwegian Ministry of Foreign Affairs, United Nations Development Programme, and the World Bank Global Facility for Disaster Reduction and Recovery (GFDRR), the Huairou Commission provides funding, resources, and training to amplify and scale the work of existing or semiorganized coalitions at the local and community levels.
Indonesia

The

Philippines
Kenya's County Climate Change Funds, 2011-2014, scaling phase: 2018-2022
Kenya

The Kenya County Climate Change Fund mechanism, initially piloted as the Climate Adaptation Fund in Isiolo County and subsequently scaled out to the counties of Garissa, Kitui, Makueni, and Wajir, is a pioneering mechanism to facilitate the flow of climate finance to county governments to empower local communities. ${ }^{p}$ It has involved strengthening public participation in the management and use of those funds to build their resilience to a changing climate. ${ }^{9}$

\section{LOCALLY LED CHARACTERISTICS}

In Guatemala and Honduras, resilience-building practices are designed and implemented by women from grassroots groups. Thanks to the success of the project, they were subsequently invited as expert practitioners to collaborate with government ministries and train other women. ${ }^{k}$

Implemented by the Unión de Cooperativas de Mujeres Productoras Las Brumas, Nicaraguan women leveraged the funds to start new initiatives or expand and deepen existing ones to reduce the women farmers' economic risks from floods and droughts. Women were trained to map risk and vulnerabilities in their communities, and these maps were used to identify priorities in the types of agricultural practice solutions that would be deployed!

Grassroots women's groups in Indonesia used the grants to set up 12 grocery stores in their villages to deal with income and food insecurity from continual climate shocks. ${ }^{\mathrm{m}}$

Participating Philippine communities had already established a savings and credit practice where communities pooled their savings and provided loans to members. Members used CRF loans to improve their various sources of livelihood (e.g., farming, fishing, running sari-sari shops, raising livestock). ${ }^{n}$ These community-managed funds were used in community-led negotiations with local municipalities to show that communities were optimizing the use of grants. ${ }^{0}$

The pilot's objective was to improve climate finance flows to newly formed county governments, while empowering local communities via public participation in the design and use of these funds. The pilot showed that, when financially and technically prepared, local governments can identify and manage investments that meet both local and adaptation priorities. The mechanism was further refined by the Ada Consortium to establish local adaptation planning committees, tools to integrate climate into county plans and legislation, and a monitoring and evaluating system that embedded community-led review of programs. ${ }^{r}$ 
Table B1 | List of Locally Led Projects and Programs Cited in This Paper (Cont.)

\section{INTERVENTION OR FUND NAME \\ LOCATION \\ BRIEF DESCRIPTION \\ LOCALLY LED CHARACTERISTICS}

Myanmar Alliance initiative, Myanmar 2015-18
The Myanmar Alliance initiative was a $£ 5$ million grant project awarded to BRACED by the United Kingdom's Department for International Development to strengthen community preparedness, response, and ability to adapt to climate extremes and disasters. The program implemented activities based on the immediate and urgent needs of the communities, prioritizing women and children as key drivers of community resilience and sustainable development. ${ }^{\mathrm{s}}$ It was implemented by an alliance led by Plan International Myanmar and composed of five other agencies: ActionAid, World Vision, BBC Media Action, Myanmar Environment Institute, and UN-Habitat.

Tajikistan Climate Resilience Tajikistan
Financing Facility
(CLIMADAPT), 2016-Present

(CLIMADAPT), 2016-Present

Urban Poor Fund International (UPFI), 2008-Present
CLIMADAPT is a US\$10 million credit line program that involves the government of Tajikistan, the Climate Investment Funds, and the United Kingdom. It is a pilot initiative to facilitate access to climate resilience technologies improving the use of water, energy, and land resources in Tajikistan. ${ }^{\text {. The credit }}$ line seeks to make the private sector more resilient and operates through Tajik banks and microfinance institutions for on-lending to small businesses, farmers, and households through local financial institutions.
The project facilitated prioritizing and selecting appropriate resilience-building measures to address urgent and immediate needs at the community level, establishing active and open spaces for vulnerable groups, like women and children, to lead on the project's decision-making and planning. The initiative sought to shift community-level power dynamics, ensuring that women's voices were integrated into the decisionmaking structures of the resilience planning processes and subnational mechanisms for multistakeholder resilience planning. ${ }^{t}$

Resilience-building technology and measures were vetted and listed by CLIMADAPT but it was the communities and individuals themselves who decided on a specific adaptation measure based on whether the solution was responsive and appropriate for their needs and livelihoods. These investments save in the region of 50 gigawatthours per year of primary energy and 13 million cubic meters of water annually, and prevent soil erosion estimated to be about 695 tons/year.

With the founding proposition that people in poverty are central actors in urban development and poverty eradication, the fund recognizes that these communities are best able to choose and co-manage their own urban improvement programs. Communities have direct control of capital to enable them to negotiate with formal bodies such as government and banks. By the end of its third year, in 2010, UPFI had funded the building of over 4,000 homes, secured tenure for 30,000 families, used \$6.3 million for over 100 projects in 16 countries, and brought about policy changes in its various focus areas. ${ }^{x y}$

Notes:

a. Leavy et al. 2018, b. Leavy et al. 2018, c. World Bank 2019, d. World Bank n.d, e. DCF Alliance 2019, f. Avina Foundation 2017, g. Avina Foundation 2017, h. Avina Foundation 2017, i. Madajewicz, 2013, j. Madajewicz 2013, k. Smith et al. 2014, l. Huairou Commission 2016, m. Rodriguez 2010, n. ADB 2017, o. Huairou Commission 2016, p. ADB 2017, q. Crick et al. 2019, r. Chaudhury et al. 2020, s. Crick et al. 2019, t. Leavy et al. 2018, u. Leavy et al. 2018, v. CIF 2018, w. CIF 2018, x. Schermbrucker et al. 2016, y. UPFI n.d. 


\section{adaptation}

climate finance

community-based adaptation

community-driven development

decentralization

devolution

direct access and enhanced direct access

\section{locally led adaptation}

Climate adaptation is the process of adjusting to present or future climate and its effects. Adaptation aims to mitigate or avoid harm from climate change and where possible exploit beneficial opportunities (IPCC 2014).

Public and private finance that funds climate adaptation and mitigation action (IIED 2017).

Community-based adaptation (CBA) is an empowerment-based approach to adaptation that, via participatory processes, encourages community-level leadership in assessing risks, planning strategies, prioritizing resources, and implementing and monitoring adaptation measures (Mfitumukiza et al. 2020).

Community-driven development (CDD) programs "operate on the principles of transparency, participation, local empowerment, demand-responsiveness, greater downward accountability, and enhanced local capacity" (World Bank 2020).

Decentralization involves the transfer of public authority, resources, and personnel from the national level to subnational jurisdictions, bringing administrative, political, and fiscal planning and decision-making closer to citizens and increasing participation

Devolution is a significant, authorized, and permanent transfer of capacity and/or powers from the central government to subnational governing institutions with often constitutionally mandated legislative and decision-making powers.

In the direct access approach, oversight, management, and implementation of activities are delegated by a global fund to the national level via vetted entities that then work closely together to develop work programs, concept notes, and project development capacities (GCF n.d.).

With enhanced direct access approaches, oversight, management, and implementation are delegated by the global fund to the national level (Müller 2013). A degree of oversight is maintained at the international level to report on the fund's activities and ensure good practices, but specific projects are proposed or decided by the executing entities, allowing more stakeholder-driven and locally led adaptation (GCF 2019; Müller 2013).

Locally led adaptation is climate adaptation action in which local communities, community-based organizations, citizen groups, local government, and local private sector entities at the lowest administrative structure are key decision-makers in the interventions that affect them. These local actors have leadership roles that include decision-making powers to identify resources and priorities needed, investments to be made, and who to involve in the design, execution, and monitoring and evaluation of projects and programs (Mfitumukiza et al. 2020). Locally led adaptation goes beyond community engagement and applies only when local actors have agency and decision-making power on how to address climate impacts. It features deliberate efforts to incorporate social equity and inclusion principles. 
1. Despite the global spotlight in recent years on Nature-based Solutions (NbS), an umbrella term that encompasses EbA activities, none of the locally led projects reviewed referred to this approach. A reason for this could be that NbS concepts as they are discussed today by the international community are still relatively new, meaning they have not had time to feature in past or recently evaluated projects.

2. A theory of change is a specific type of methodology for planning, participation, and evaluation that is used to promote social change. It defines long-term goals and identifies necessary preconditions that will allow such change to come to fruition.

\section{REFERENCES}

ADB (Asian Development Bank). 2017. Accelerating Sustainable Development: Investing in Community-Led Strategies for Climate and Disaster Resilience. https://www.adb.org/sites/default/files/project-documents/47228/47228-001-dpta-en_4.pdf.

ADB. 2019. Community Resilience Partnership Program: Supporting Investments in Resilience That Reach Scale while Ensuring No One Is Left Behind. Scoping Study.

Agrawal, A., C. Costella, N. Kaur, J. Tenzing, C. Shakya, and A. Norton. 2019. "Climate Resilience through Social Protection." Background paper to the 2019 report of the Global Commission on Adaptation (GCA). Rotterdam and Washington, DC: GCA. https://cdn.gca.org/assets/2019-09/ClimateResiliencethroughSocialProtection.pdf.

Amerasinghe, N., J. Thwaites, G. Larsen, and A. Ballesteros. 2017. The Future of the Funds: Exploring the Architecture of Multilateral Climate Finance. Washington, DC: World Resources Institute. https://wriorg.s3.amazonaws.com/ s3fs-public/The_Future_of_the_Funds_0.pdf.

Archer, D., W. Monteith, H. Scottand, and S. Gawler. 2017. Developing City Resilience Strategies: Lessons from the ICLEI-ACCCRN Process. London: International Institute for Environment and Development. https://pubs.iied. org/pdfs/10816llED.pdf.

Avina Foundation. 2017. Annual Report 2017. https://www.avina.net/wp-content/uploads/2019/03/2017-eng.pdf.

Balala, C.E. 2019. "COA Reminds LGUs on Usage of Calamity Funds." Manila: Philippine Information Agency, Republic of the Philippines. https://pia.gov.ph/ news/ articles/1025909.

Barnard, S. 2015. "Climate Finance for Cities: How Can International Climate Funds Best Support Low-Carbon and Climate Resilient Urban Development?" Working Paper 419. London: Overseas Development Institute. https://www. odi.org/sites/odi.org.uk/files/odi-assets/publications-opinion-files/9660.pdf.
Caravani, A., S. Greene, N. Canales Trujillo, and A. Amsalu. 2017. "Decentralising Climate Finance: Insights from Kenya and Ethiopia." BRACED Working Paper. London: BRACED, https://www.odi.org/sites/odi.org.uk/files/resource-documents/11804.pdf.

Chaudhury, M., T. Summerlin, and N. Ginoya. 2020. Mainstreaming Climate Change Adaptation in Kenya: Lessons from Makueni and Wajir Counties. Washington, DC: World Resources Institute. https://www.wri.org/publication/mainstreaming-climate-change-adaptation-kenya.

CIF (Climate Investment Funds). 2018. Microfinance for Climate Adaptation: From Readiness to Resilience. CIF Research Brief. https://www.climateinvestmentfunds.org/sites/cif_enc/files/knowledge-documents/micro-finance_ research_brief.pdf.

Crick, F., C. Hesse, V. Orindi, M. Bonaya, and J. Kiiru. 2019. "Delivering Climate Finance at the Local Level to Support Adaptation: Experiences of County Climate Change Funds in Kenya." Working Paper. Nairobi: Ada Consortium. https://pubs.iied.org/G04415/.

DCF Alliance. 2019. "The Devolved Climate Finance Mechanisms: Principles, Implementations and Lessons from Four Semi-arid Countries." Working paper. The DCF Alliance.

De Coninck, S., J. Abrams, J. Dendura, U. Norbu, J. Steffensen, C.S. Tramunt, and H. Visser. 2018. Financing Local Adaptation to Climate Change: Experiences with Performance-Based Climate Resilience Grants, 2018. 2nd edition. New York: United Nations Capital Development Fund. https://www.uncdf. org/article/4685/experiences-with-performance-based-climate-resilience-grants-2018.

Dinshaw, A., and C. McGuinn. 2019. "Assessing the Effectiveness of Climate Resilience Grants to Local Governments in Least Developed Countries." Working Paper. Washington, DC: World Resources Institute. https://www.wri. org/publication/assessing-effectiveness-climate-resilience.

Fairman, D., C. Morris, M. Ferenz, T. Berkman, and A. Rowe. 2020. Local Stakeholder Engagement in the Climate Investment Funds: Evaluation Report. Cambridge, MA: Consensus Building Institute. https://www.climateinvestmentfunds.org/sites/cif_enc/files/knowledge-documents/evaluation_of_local_stakeholder_engagement_in_the_cif.pdf.

Floater, G., D. Dowling, D. Chan, M. Ulterino, J. Braunstein, T. McMinn, and E. Ahmad. 2018. Global Review of Finance for Sustainable Urban Infrastructure. Background Paper. London and Washington, DC: New Climate Economy Coalition for Urban Transitions. https://newclimateeconomy.report/workingpapers/wp-content/uploads/sites/5/2018/01/NCE2017_CUT_GlobalReview_02012018.pdf. 
GCA (Global Commission on Adaptation). 2019. Adapt Now: A Global Call for Leadership on Climate Resilience. https://gca.org/global-commission-on-adaptation/report.

GCF (Green Climate Fund). n.d. "GCF in Brief: Direct Access." Accessed September 2020. https://www.greenclimate.fund/sites/default/files/document/ gcf-brief-direct-access_0.pdf.

GCF. 2019. "GCF in Brief: Enhancing Direct Access." https://www.greenclimate.fund/sites/default/files/document/gcf-brief-enhancing-direct-access_0.pdf.

GEF (Global Environment Facility). n.d. "GEF Small Grants Programme." Accessed November 16, 2020. https://www.thegef.org/topics/gefsgp.

GEF and UNDP (Global Environment Facility and United Nations Development Programme). 2020. GEF Small Grants Programme (SGP) Annual Monitoring Report: Report Highlights, Reporting Year 2019-2020. Washington, DC, and New York: GEF and UNDP. https://sgp.undp.org//innovation-library/item/ download/2205_1d69fda4cbdc7d69757158c48aeae072.html.

Hesse, C. 2016. "How Devolved Climate Finance Can Deliver Climate Resilience at Local Level." News, International Institute for Environment and Development, https://www.iied.org/how-devolved-climate-finance-can-deliver-climate-resilience-local-level.

Huairou Commission. 2016. Huairou Commission: Annual Report 2014. Cabuyao, Philippines: Huairou Commission. https://huairou.org/old-file/ wp-content/uploads/2016/09/HCAR2014.pdf.

IBP and UNDP (International Budget Partnership and United Nations Development Programme). 2018. Budgeting for a Greener Planet: An Assessment of Climate Change Finance Accountability in Bangladesh, India, Nepal, and the Philippines. Washington, DC, and New York: IBP and UNDP. https://www. asia-pacific.undp.org/content/rbap/en/home/library/democratic_governance/budgeting-for-a-greener-planet.html.

IIED (International Institute for Environment and Development). 2017. Going Local: Fast Tracking Climate Finance to the Most Vulnerable. Background Paper. London: IIED. https://pubs.iied.org/pdfs/17441IIED.pdf.

IIED. 2020. "Calling for Business Unusual: Mechanisms for Delivering Change." Briefing, London: IIED. https://pubs.iied.org/pdfs/17749IIED.pdf.

IIED. Forthcoming (2021). Adaptation as Business-Unusual: Endorsement of Principles for Locally-Led Adaptation Action. London: IIED.

IIED, Ada Consortium, Near East Foundation, Innovations Environment Africa, et al. 2017. Devolved Climate Finance: An Alliance of Government and Non-government Organisations Promoting Community-Prioritised Investment for Climate Adaptation. https://pubs.iied.org/pdfs/17440IIED.pdf.
IIED, United Nations Capital Development Fund, Ada Consortium, Near East Foundation, and Innovation, Environnement et Développement en Afrique. 2016. "Decentralising Climate Finance to Reach the Most Vulnerable." https:// pubs.iied.org/pdfs/G04103.pdf.

IPCC (International Panel on Climate Change). 2014. Climate Change 2014: Synthesis Report. Contribution of Working Groups I, II and III to the Fifth Assessment Report of the Intergovernmental Panel on Climate Change (Core Writing Team: R.K. Pachauri and L.A. Meyer [eds.]), Geneva, Switzerland: IPCC. https://www.ipcc.ch/report/ar5/syr/.

Kapos, V., S. Wicander, T. Salvaterra, K. Dawkins, and C. Hicks. 2019. The Role of the Natural Environment in Adaptation. Background Paper for the Global Commission on Adaptation. Rotterdam and Washington, DC: Global Commission on Adaptation. https://cdn.gca.org/assets/2019-12/RoleofNaturalEnvironmentinAdaptation_V2.pdf.

Leavy, J., E. Boydell, S. McDowell, and B. Sladkova. 2018. Resilience Results: BRACED Final Evaluation. Building Resilience and Adaptation to Climate Extremes and Disasters (BRACED) Synthesis Paper. East Sussex, United Kingdom: Itad. https://itad.com/wp-content/uploads/2018/09/BRCJ6513-Final-Evaluation-report-1709-WEB.pdf.

LIFE-AR (LDC Initiative for Effective Adaptation and Resilience). 2019. Delivering Our Climate-Resilient Future: Lessons from a Global Evidence Review. http://www.Idc-climate.org/wp-content/uploads/2019/09/web_LDCevidencereview.pdf.

Lorimer, E. 2019. Learning from Each Other in the Community Adaptation Small Grants Facility Project (South Africa). Adaptation Fund NGO Network، https:// af-network.org/5445.

Madajewicz, M., A. Tsegay, and M. Norton. 2013. Managing Risks to Agricultural Livelihoods: Impact Evaluation of the HARITA Programme in Tigray, Ethiopia, 2009-2012. Evaluation Report. Addis Ababa: Oxfam America. https:// s3.amazonaws.com/oxfam-us/www/static/media/files/0xfam_America_Impact_Evaluation_of_HARITA_2009-2012_English.pdf.

Measham, T.G., B.L. Preston, T.F. Smith, C. Brooke, R. Gorddard, G. Withycombe, and C. Morrison. 2011. "Adapting to Climate Change through Local Municipal Planning: Barriers and Challenges." Mitigation and Adaptation Strategies for Global Change 16: 889-909.

Mfitumukiza, D., A.S. Roy, B. Simane, A. Hammill, M.F. Rahman, and S. Huq. 2020. Local Action and Community-Based Adaptation. Background report for the Locally Led Action Track. Rotterdam and Groningen, The Netherlands: Global Commission on Adaptation.

Müller, B. 2013. "'Enhanced (Direct) Access' through '(National) Funding Entities'-Etymology and Examples." Information Note on the Green Climate Fund Business Model Framework. Oxford: University of Oxford. https://oxfordclimatepolicy.org/sites/default/files/EnhancedDirectAccess-04-2013_0.pdf. 
Musah-Surugu, I.J, A. Ahenkan, and J.N. Bawole. 2017. "Too Weak to Lead: Motivation, Agenda Setting and Constraints of Local Government to Implement Decentralized Climate Change Adaptation Policy in Ghana." Environment, Development and Sustainability 21 (2): 587-607. D0l: 10.1007/s10668-017-0049-z.

Olhoff, A., B. Dickson, D. Puig, K. Alverson, and S. Bee. 2016. The Adaptation Finance Gap Report. Nairobi: United Nations Environment Programme. https:// unepdtu.org/publications/the-adaptation-finance-gap-report/.

Patel, S., M. Soanes, F. Rahman, B. Smith, and D. Steinbach. 2020. "Good Climate Finance Guide: Lessons for Strengthening Devolved Climate Finance." Working Paper. London: International Institute for Environment and Development.

Reid, H. 2016. "Ecosystem- and Community-Based Adaptation: Learning from Community-Based Natural Resource Management." Climate and Development 8 (1): 4-9. D0I: 10.1080/17565529.2015.1034233.

Reid, H., and S.S. Alam. 2014. "Ecosystem-Based Approaches to Adaptation: Evidence from Two Sites in Bangladesh." Working Paper. London: International Institute for Environment and Development. https://pubs.iied. org/10115IIED/.

Resch, E., S. Allan, L. Giles Alvarez, and H. Bisht. 2017. Mainstreaming, Accessing and Institutionalising Finance for Climate Change Adaptation. Learning Paper. Oxford, United Kingdom: Action on Climate Today. http:// www.acclimatise.uk.com/wp-content/uploads/2018/02/OPM_ACT_LP_finance_for_climate_change_adaptation_FFRG.pdf.

Restle-Steinert, J., T. Hausotter, S. Rudolph, A. Cochu, and D. Tänzler. 2019. Steering International Adaptation Finance towards the Local Level. Scoping Paper. Berlin: Adelphi. https://www.adelphi.de/en/system/files/mediathek/ bilder/adelphi-2019_Scoping-Paper_Steering-AdaptFin-Towards-Local-Level.pdf.

Rodriguez, H. 2010. "Community Resilience Fund: Partnering with Grassroots Women to Fast-Track Risk Reduction and Adaptation." PPT Presentation. Cooperative Las Brumas, Huairou Commission, and GROOTS International, https://www.cbd.int/cooperation/pavilion/cancun-presentations/2010-12-9-Rodriguez-en.pdf.

Schermbrucker, N., S. Patel, and N. Keijzer. 2016. "A View from Below: What Shack Dwellers International (SDI) Has Learnt from Its Urban Poor Fund International (UPFI)." International Journal of Urban Sustainable Development 8 (1): 83-91. DOI: 10.1080/19463138.2015.1046075.

Smith, B., D. Brown, and D. Dodman. 2014، "Reconfiguring Urban Adaptation Finance." Working Paper. London: International Institute for Environment and Development. https://pubs.iled.org/pdfs/10651IIED.pdf.

Soanes, M., C. Shakya, A. Walnycki, and S. Greene. 2019. Money Where It Matters: Designing Funds for the Frontier. Issue Paper. London: International Institute for Environment and Development. https://pubs.iied.org/ pdfs/10199||ED.pdf.
Tenzing, J. 2020. "Integrating Social Protection and Climate Change Adaptation: A Review." WIREs Climate Change 11 (2): e626. https://doi.org/10.1002/ wcc.626.

Tye, S., J. Waslander, and M. Chaudhury. 2020. "Building Coastal Resilience in Bangladesh, the Philippines, and Colombia: Country Experiences with Mainstreaming Climate Adaptation." Working Paper. Washington, DC: World Resources Institute. www.wri.org/publication/building-coastal-resilience.

UNDP (United Nations Development Programme Bureau for Development Policy). 2010. Designing Climate Change Adaptation Initiatives: A UNDP Toolkit for Practitioners. New York: UNDP. https://sustainabledevelopment.un.org/ content/documents/951013_Toolkit\%20for\%20Designing\%20Climate\%20 Change\%20Adaptation\%20Initiatives.pdf.

UNDP and GEF (United Nations Development Programme and Global Environment Facility Independent Evaluation Offices). 2015. Evaluation of the Small Grants Programme. New York and Washington, DC: UNDP and GEF. http:// www.gefieo.org/sites/default/files/ieo/evaluations/sgp-2015-summary-eng. pdf.

UPFI (Urban Poor Fund International). n.d. "About the UPFI." Accessed October 2020. http://upfi.info/about/.

Walnycki, A. 2015. "The Architecture of Aid." London: International Institute for Environment and Development. https://www.iied.org/files/kiln/architecture-of-aid.html.

World Bank. n.d. "Ethiopia Climate Action through Landscape Management (CALM)-Technical Assessment." Washington, DC: World Bank. Accessed August 2020. http://documents1.worldbank.org/curated/ en/154531558461396734/pdf/Final-Technical-Assessment-ETHIOPIA-CLIMATE-ACTION-THROUGH-LANDSCAPE-MANAGEMENT-PROGRAM-FOR-RESULTS-P170384.pdf.

World Bank. 2019. "To Meet Its Climate Resilience and Mitigation Goals, Ethiopia Gets a $\$ 500$ Million Grant from the World Bank." Semonegna. https:// semonegna.com/ethiopia-climate-action-through-landscape-management-calm-program/.

World Bank. 2020. "Community-Driven Development." Last updated October 1. https://www.worldbank.org/en/topic/communitydrivendevelopment\#1. 


\section{ACKNOWLEDGMENTS}

We are pleased to acknowledge our institutional strategic partners that provide core funding to WRI: the Netherlands Ministry of Foreign Affairs, Royal Danish Ministry of Foreign Affairs, and Swedish International Development Cooperation Agency.

The authors would like to thank many individuals-technical experts, civil society representatives, members of multilateral institutions such as the Asian Development Bank, and members of the Global Commission on Adaptation's Locally Led Action Track-for their valuable insights and contributions in the consultation and interview stages of this research.

We would further like to thank Tamara Coger, Cristina Dengel, David Gibbs, Demetrio Innocenti, Gaia Larsen, Ayushi Trivedi, Sally Tyldesley, and Ani Waiba for their thoughtful feedback and comments during the peer review process for this paper. We are also grateful to Christina Chan and Cristina Rumbaitis del Rio for their insightful guidance and support at every stage of research, writing, and revising.

\section{ABOUTTHE AUTHORS}

Stefanie Tye is a research associate with the Climate Resilience Practice at WRI. She works on a range of topics, including transformative adaptation in the agriculture sector, mainstreaming adaptation, and providing countries with technical assistance on strengthening climate resilience.

\section{Contact: stye@wri.org}

Isabella Suarez is a consultant with the Global Commission on Adaptation, and previously served as strategic engagement coordinator for the Commission's WRI Secretariat. Her research interests center on the synergies of climate mitigation and adaptation, as well as devolved finance.

\section{ABOLJT WRI}

World Resources Institute is a global research organization that turns big ideas into action at the nexus of environment, economic opportunity, and human well-being.

\section{Our Challenge}

Natural resources are at the foundation of economic opportunity and human wellbeing. But today, we are depleting Earth's resources at rates that are not sustainable, endangering economies and people's lives. People depend on clean water, fertile land, healthy forests, and a stable climate. Livable cities and clean energy are essential for a sustainable planet. We must address these urgent, global challenges this decade.

\section{Our Vision}

We envision an equitable and prosperous planet driven by the wise management of natural resources. We aspire to create a world where the actions of government, business, and communities combine to eliminate poverty and sustain the natural environment for all people.

\section{Our Approach}

\section{COUNT IT}

We start with data. We conduct independent research and draw on the latest technology to develop new insights and recommendations. Our rigorous analysis identifies risks, unveils opportunities, and informs smart strategies. We focus our efforts on influential and emerging economies where the future of sustainability will be determined.

\section{CHANGE IT}

We use our research to influence government policies, business strategies, and civil society action. We test projects with communities, companies, and government agencies to build a strong evidence base. Then, we work with partners to deliver change on the ground that alleviates poverty and strengthens society. We hold ourselves accountable to ensure our outcomes will be bold and enduring.

\section{SCALE IT}

We don't think small. Once tested, we work with partners to adopt and expand our efforts regionally and globally. We engage with decision-makers to carry out our ideas and elevate our impact. We measure success through government and business actions that improve people's lives and sustain a healthy environment.

creative Copyright 2021 World Resources Institute. This work is licensed under the Creative Commons Attribution 4.0 International License

cc)commons (i) To view a copy of the license, visit http://creativecommons.org/licenses/by/4.0/ 